\title{
Current clinical practices in stroke rehabilitation: Regional pilot survey
}

\author{
Pradeep Natarajan, PhD; ${ }^{*}$ Ashley Oelschlager, DPT; ${ }^{2}$ Arvin Agah, PhD; ${ }^{1}$ Patricia S. Pohl, PhD, PT; $^{2}$ \\ S. Omar Ahmad, PhD; ${ }^{3}$ Wen Liu, PhD $^{2}$ \\ ${ }^{1}$ Department of Electrical Engineering and Computer Science, The University of Kansas, Lawrence, KS; Departments \\ of ${ }^{2}$ Physical Therapy and Rehabilitation Science and ${ }^{3}$ Occupational Therapy Education, The University of Kansas \\ Medical Center, Kansas City, KS
}

\begin{abstract}
This study was aimed at understanding the current physical and occupational therapy practices in stroke rehabilitation in the Midwest. The insights gained from this pilot study will be used in a future study aimed at understanding stroke rehabilitation practices across the nation. Researchers and clinicians in the field of stroke rehabilitation were interviewed, and past studies in the literature were analyzed. Through these activities, we developed a 37-item questionnaire that was sent to occupational and physical therapists practicing in Kansas and Missouri who focus on the care of people who have had a stroke $(n=320)$. A total of 107 respondents returned a completed questionnaire, which gives a response rate of about $36 \%$. The majority of respondents had more than 12 years of experience treating patients with stroke. Consensus of $70 \%$ or more was found for $80 \%$ of the items. The preferred approaches for the rehabilitation of people who have had a stroke are the Bobath and Brunnstrom methods, which are being used by $93 \%$ and $85 \%$ of the physical and occupational therapists, respectively. Even though some variability existed in certain parts of the survey, in general clinicians agreed on different treatment approaches in issues dealing with muscle tone, weakness, and limited range of motion in stroke rehabilitation. Some newer treatment approaches that have been proven to be effective are practiced only by a minority of clinicians. The uncertainty among clinicians in some sections of the survey reveals that more evidence on clinical approaches is needed to ensure efficacious treatments.
\end{abstract}

Key words: CIMT, current practices, NDT, occupational therapist, physical therapist, PNF, questionnaire, rehabilitation, stroke, survey.

\section{INTRODUCTION}

Every 45 seconds someone in the United States has a stroke. Stroke is a leading cause of serious long-term disability. From the early 1970s to the early 1990s, the estimated number of noninstitutionalized stroke survivors increased from 1.5 to 2.4 million, and an estimated 4.7 million stroke survivors are alive today [1]. Approximately 50 to 60 percent of stroke survivors are moderately or minimally impaired, and these individuals may greatly benefit from rehabilitation [2-5].

Historically, several treatment approaches have been introduced and adopted by physical and occupational therapists. The stroke rehabilitation methods adopted by therapists vary widely depending on their background knowledge, clinical experience, clinical skills, and personal preferences [6-9]. The availability of a plethora of treatment methods shows that stroke rehabilitation

\footnotetext{
Abbreviations: CIMT = constraint induced movement therapy, KUMC = University of Kansas Medical Center, NDT $=$ neurodevelopmental treatment, $\mathrm{PNF}=$ proprioceptive neuromuscular facilitation.

*Address all correspondence to Pradeep Natarajan, PhD; c/o Wen Liu, PhD; Department of Physical Therapy and Rehabilitation Science, University of Kansas Medical Center, 3901 Rainbow Blvd, Mail Stop 2002, Kansas City, KS 66160; 785-550-3797; fax: 913-588-4568.

Email: pradeeppradeep@gmail.com

DOI: 10.1682/JRRD.2007.04.0057
} 
practices are continually evolving. Previous studies conducted in the United Kingdom used surveys to determine common treatment practices in stroke rehabilitation among physical therapists [10-11]. These studies aimed to identify key theoretical beliefs underlying physical therapy treatment of stroke. While considering theoretical beliefs that drive treatment, we must also contemplate another important aspect, the delivery of treatment. Given the broad range of therapy approaches, educators and researchers must obtain data on which stroke rehabilitation methods are actually being used by clinicians. In the United States, studies have been conducted to understand some of the physical and occupational therapy practices in stroke rehabilitation [12-16]. However, all these studies are focused on aspects of rehabilitation at inpatient facilities [12-16]. The studies conducted by Latham et al. and Richards et al. concluded that the occupational therapy provided consisted of multiple treatment approaches [12-13]. The therapists provided functional task training as well as motor training, and they tailored therapy based on the patients' functional abilities. The studies conducted by Latham et al. and Jette et al. showed that physical therapy at inpatient facilities generally consisted of task-based training and therapists adapted their treatment according to the patients' abilities [14-15]. The results from these studies provide good insight into stroke rehabilitation practices at inpatient facilities in the United States. However, one can realize that further research would provide a better understanding of the theoretical beliefs of therapists and the underlying reasons for the therapists' choice of treatment at both long-term outpatient and short-term inpatient facilities. We must also discuss whether these approaches are supported by sufficient evidence given the fact that all rehabilitation professionals are moving toward evidence-based practice. Information on current practices and their supporting evidence may greatly affect the decisions of policy makers and the desire of professionals to deliver the best continuing education and make current clinical practices more effective. Finally, understanding the current practices may also enable the development of an intelligent robotic stroke rehabilitation system. Robot-aided stroke rehabilitation is the current frontier of the field. The knowledge collected from clinical experts may help researchers design an optimal control system that guides the motion of a robotic arm in terms of its position, velocity, and forces when used in motor training of stroke survivors.

Surveys have been conducted in countries including Sweden, Australia, and the United Kingdom to determine the clinical practices and the underlying theoretical beliefs in stroke rehabilitation [6-8]. A survey has been conducted in the United States to understand in particular the current practices of clinicians who use the neurodevelopmental treatment (NDT) method [10]. While these surveys give some idea about the practices in stroke rehabilitation, many of them are either outdated or narrow in their scope and therefore not representative of current practices in the United States. This pilot study is aimed at understanding the current stroke rehabilitation practices of physical and occupational therapists who are providing care in two Midwestern states: Kansas and Missouri.

\section{METHODS}

\section{Questionnaire}

Initially, we conducted interviews with a few clinical researchers and clinicians who are working in the field of stroke rehabilitation. We developed a questionnaire based on their suggestions and from previous studies conducted in stroke treatment methods [6,9-10]. The questionnaire consisted of 37 items (see Appendix, available online only at http://www.rehab.research.va.gov/jour/08/45/6/pdf/ contents.pdf) and was divided into six sections. Questions were included that pertained to the background information of the clinicians, their treatment aims, how the clinicians treat tone, their approach to facilitate movement and function, and some specific questions about motor rehabilitation. After preparing a draft version of the questionnaire, we conducted interviews with the researchers for a second time to discuss the questionnaire. Modifications were made according to their suggestions. The final version of the questionnaire consisted of closeended questions (a write-in option of "other" was included where appropriate) to make the questionnaire easier to complete and more objective. The final version of the questionnaire and the accompanying cover letter were approved by the institutional review board at the University of Kansas Medical Center (KUMC).

\section{Survey Protocol}

Contact information of physical therapy and occupational therapy clinicians and clinical sites in the states of Kansas and Missouri was provided by the Department of Physical Therapy and Rehabilitation Science and the Department of Occupational Therapy Education at KUMC. In May 2006, the questionnaire, along with a 
cover letter and a postage-paid return envelope, was sent to 320 clinicians and clinical sites. The clinicians contacted were neither limited to nor associated with any one particular organization or institution. They represented various hospitals, clinics, and rehabilitation centers in Kansas and Missouri. The cover letter explained to the participants the aim of this study and that responding to the survey was entirely voluntary. Since the questionnaire itself did not contain any individually identifying questions, it posed no risk to the participants' privacy in any way. When the surveys were received back from the participants, we assigned the surveys an identification number (for future data verification purposes) and stored them in a secure place. The number of responses received for the survey was considered sufficient, and hence, no reminder of any kind was sent to those who did not respond.

\section{Survey Analysis}

The survey responses were manually entered in a Microsoft Office Excel spreadsheet (Microsoft Corp; Redmond, Washington) and analyzed with Excel, MATLAB $^{\circledR}$ (The MathWorks, Inc; Natick, Massachusetts), and Weka data mining tools [17]. Out of the 320 questionnaires sent out, 9 were returned as undeliverable because of multiple reasons and 7 were returned unused because the respondents stated that they did not have experience in stroke rehabilitation. A total of 110 respondents returned a completed questionnaire, which gives a response rate of 36.2 percent. Of these 110, however, 3 respondents who completed the questionnaire also indicated that they did not have any experience in stroke rehabilitation. Their responses were excluded, and the remaining 107 responses were analyzed. Out of the 107 respondents, at least 106 answered each question pertaining to aim of treatment, tone, facilitation of movement, and function, which gives an incompletion rate of less than 1 percent for each question in those sections. For the section that posed specific questions in motor rehabilitation, 102 or more respondents answered each question, which gives an incompletion rate of less than 4.6 percent for each question.

\section{RESULTS}

\section{Profile of Respondents}

Of the 107 clinicians who met the inclusion criteria, 55 were physical therapists, 51 were occupational thera- pists, and 1 clinician was certified in both physical and occupational therapy. Out of the 103 clinicians who specified their educational background, 47 had a master's degree or higher and 56 had a bachelor's degree. Ninety respondents specified their year of graduation from school. The respondents' median year of graduation with their terminal degree was 1996 and ranged from 1970 to 2006 (i.e., for those with only a bachelor's degree, their bachelor's graduation year was considered; for those with a master's degree, only their master's graduation year was considered; and for those with a doctorate, their doctoral graduation year was considered). The average clinical experience of the respondents working with patients with stroke was 12.6 years, with a standard deviation of 8.2 years. About 72 percent of the clinicians reported at least 8 years of experience working with patients with stroke.

\section{Background and Treatment Approach}

The clinicians were asked which treatment approach for stroke they had been taught in their professional education and which approach they use in their current practice. Their responses are shown in Figure 1. We should note that the respondents were allowed to choose multiple treatment approaches for both questions. We found that the Bobath/NDT approach and the Brunnstrom/proprioceptive neuromuscular facilitation (PNF) were the most popular

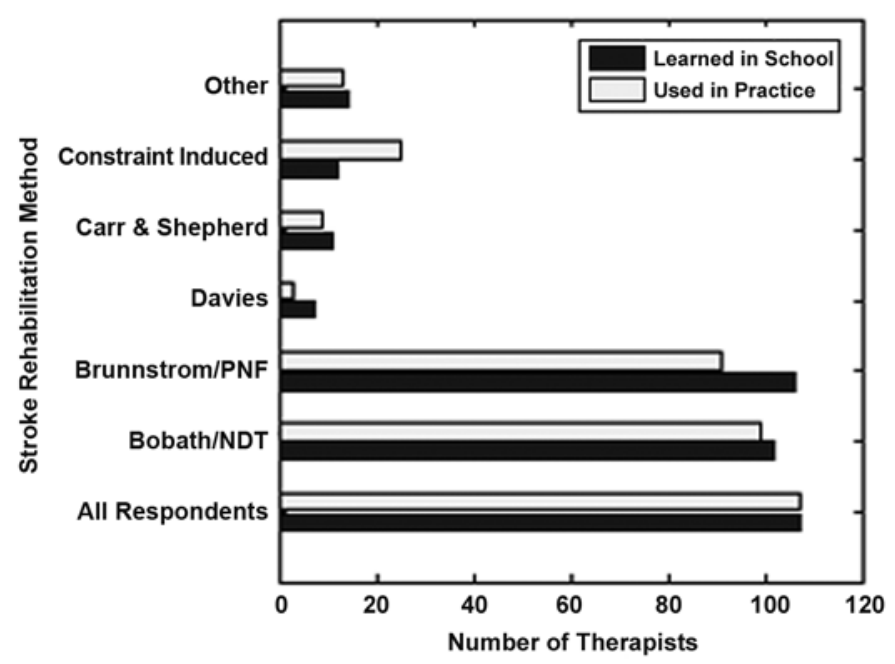

Figure 1.

Number of therapists who learned each treatment method in their school education, and number of therapists who are using each treatment method in their practice. NDT = neurodevelopmental treatment, $\mathrm{PNF}=$ proprioceptive neuromuscular facilitation. 
treatment approaches. Figure 2 shows the relationship between the year of graduation and the treatment methods taught in school. The box plot in Figure $\mathbf{3}$ shows the relationship between the years of experience treating patients with stroke and the treatment methods currently practiced. We can see from Figure 2 that Carr \& Shepherd and constraint induced approaches are recent additions to education. Figure 3 reveals that even those who did not receive formal education in these newer approaches obtained knowledge of them and adapted them into their current practice.

Out of the 106 clinicians who specified whether they treat adults or children, 76 percent worked exclusively with adults, 4 percent worked with children, and the remaining 20 percent worked with both adults and children. Approximately two-thirds (71 out of 107) of clinicians specified that they have received additional training specific to stroke rehabilitation after graduating from school. All but one of the clinicians reported participating in some form of continuing education. Only 47 out of the 107 respondents (44\%) read stroke-related professional literature on a regular basis (4 weekly and 43 monthly), while 62 respondents rarely and 2 never read the literature. However, 74 out of 107 clinicians (69\%) agreed that they incorporated concepts of motor learning from current literature in their practice, while 9 respondents disagreed and 22 were unsure.

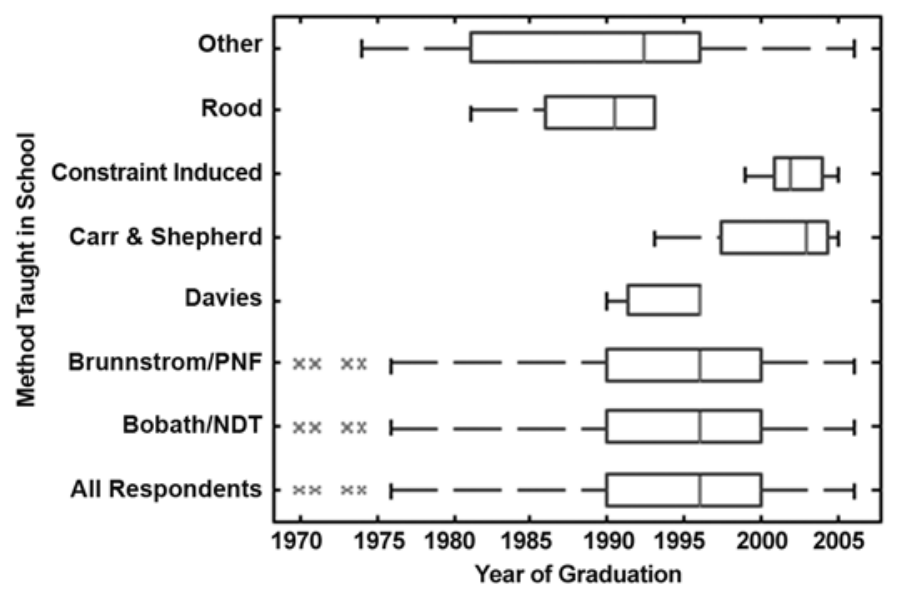

Figure 2.

Relationship between therapists' year of graduation and methods taught in their school education. NDT = neurodevelopmental treatment, $\mathrm{PNF}=$ proprioceptive neuromuscular facilitation .

\section{Aim of Treatment}

A vast majority of the clinicians (93\% or more) agreed on the main aims of physical and occupational therapy. Table 1 shows the statements presented in the questionnaire regarding the aim of treatment and the clinicians' level of agreement with the statements. Even though reeducating normal movement and facilitating adaptation to function represent different treatment approaches, 92 percent of the clinicians agreed to both aims.

\section{Pertaining to Tone}

The three statements pertaining to tone and the level of agreement of the therapists are presented in Table 2. A consensus of 79 percent or greater was found in agreement with all the statements. Even though the majority of the therapists (89\%) agreed that normalizing tone is important, they (81\%) also pointed out that it does not automatically result in movement.

\section{Facilitation of Movement}

The statements on facilitation of movement and the level of agreement of the therapists are listed in Table 3. More than 85 percent of the clinicians agreed to all the statements. The majority of the therapists (86\%) believed that while proximal stability is required, it will not necessarily result in recovery of distal movement and hence distal movement needs to be facilitated.

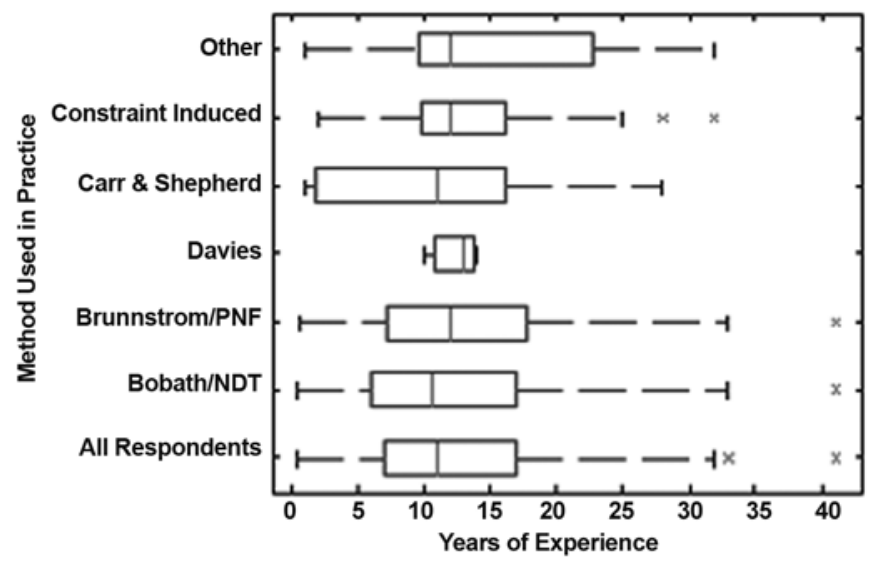

Figure 3.

Relationship between therapists' years of experience and methods used by them in their practice. NDT = neurodevelopmental treatment, $\mathrm{PNF}=$ proprioceptive neuromuscular facilitation. 
Table 1.

Survey responses of stroke rehabilitation clinicians in Kansas and Missouri $(n=107)$ regarding aim of treatment.

\begin{tabular}{|c|c|c|c|}
\hline Statement & Agree (\%) & Unsure (\%) & Disagree (\%) \\
\hline 1. Reeducate normal movement. & 99 & 1 & 0 \\
\hline 2. Facilitate postural adjustments. & 99 & 1 & 0 \\
\hline 4. Prevent secondary complications in neuromuscular function. & 94 & 5 & 1 \\
\hline
\end{tabular}

Table 2.

Survey responses of stroke rehabilitation clinicians in Kansas and Missouri $(n=107)$ pertaining to tone.

\begin{tabular}{|c|c|c|c|}
\hline Statement & Agree (\%) & Unsure (\%) & Disagree (\%) \\
\hline $\begin{array}{l}\text { 1. In patients where tone is present, normalizing tone is important } \\
\text { when facilitating movement. }\end{array}$ & 89 & 6 & 5 \\
\hline $\begin{array}{l}\text { 3. Inhibition of spasticity does not necessarily result in movement; } \\
\text { movement needs to be facilitated. }\end{array}$ & 81 & 13 & 6 \\
\hline
\end{tabular}

Table 3.

Survey responses of stroke rehabilitation clinicians in Kansas and Missouri $(n=107)$ about facilitation of movement.

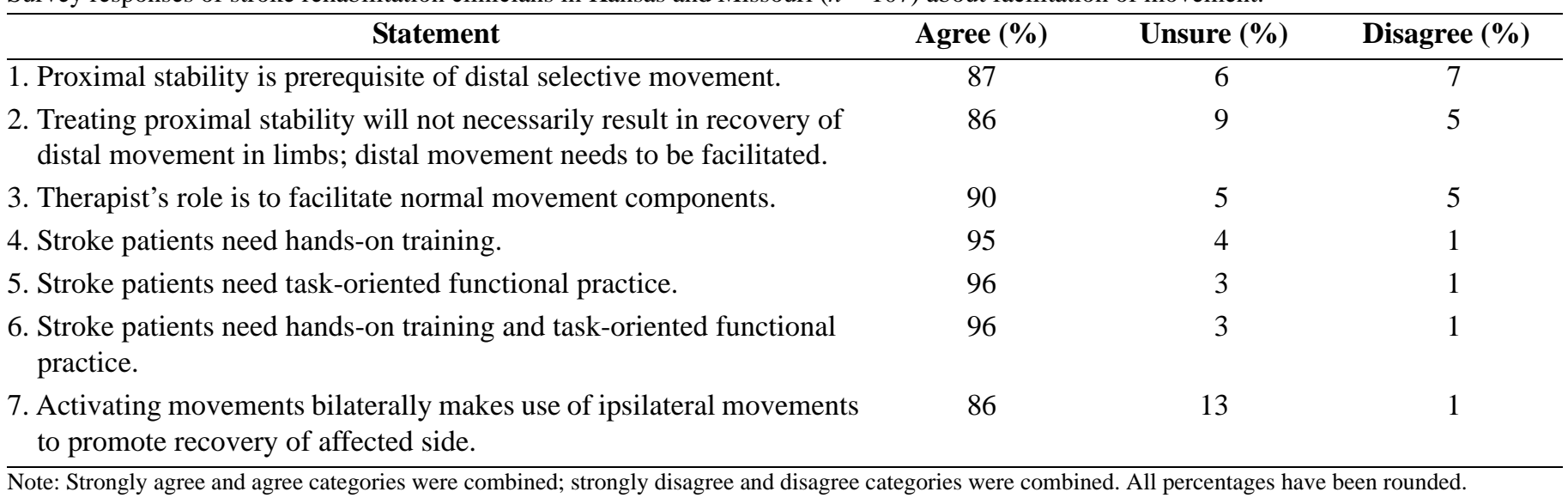

\section{Function}

Table 4 shows the statements pertaining to function and the corresponding level of agreement of the therapists. Therapists were evenly split on whether singleplane movement patterns would translate into improved function (question 3 in Table 4). More than one-quarter of respondents are unsure of what the outcome of this practice might be. Even though the majority of clinicians (63\%) believed that therapy should be delayed when abnormal movement patterns are observed, a number of them (20\%) disagreed as well.

\section{Specific Questions About Motor Rehabilitation}

Some specific statements about motor rehabilitation were presented to the clinicians, and the results are presented in Table 5. Some disagreement was found regarding the amplitude of movement that should be practiced in subjects who have limited range of motion. Two more questions pertaining to motor rehabilitation (see Appendix) were posed in the questionnaire, and the results are presented in Table 6. Clinicians were asked to rank aspects of movement that they prioritized during therapy (speed, accuracy, strength, number of repetitions, and 
Table 4.

Survey responses of stroke rehabilitation clinicians in Kansas and Missouri $(n=107)$ pertaining to function.

\begin{tabular}{|c|c|c|c|}
\hline Statement & Agree (\%) & Unsure (\%) & Disagree (\%) \\
\hline $\begin{array}{l}\text { 1. In patients where potential for recovery of normal movement exists, } \\
\text { therapists should delay performing certain activities if they are rein- } \\
\text { forcing abnormal movement patterns. }\end{array}$ & 63 & 17 & 20 \\
\hline $\begin{array}{l}\text { 2. Changing patient's ability to move does not necessarily improve } \\
\text { patient's ability to perform functional tasks. }\end{array}$ & 73 & 8 & 19 \\
\hline $\begin{array}{l}\text { 3. Intensive training of single-plane movement patterns can carry over } \\
\text { into activities of daily living. }\end{array}$ & 37 & 26 & 37 \\
\hline
\end{tabular}

Table 5.

Survey responses of stroke rehabilitation clinicians in Kansas and Missouri $(n=107)$ to specific statements about motor rehabilitation.

\begin{tabular}{|c|c|c|c|}
\hline Statement & Agree (\%) & Unsure (\%) & Disagree (\%) \\
\hline 1. Active assistive movement is useful in patients with muscle weakness. & 96 & 2 & 2 \\
\hline $\begin{array}{l}\text { 2. Patients presenting with limited active range of motion would begin } \\
\text { with small amplitude movements. }\end{array}$ & 68 & 17 & 15 \\
\hline 4. Passive range of motion is important for treatment. & 83 & 10 & 7 \\
\hline
\end{tabular}

Table 6.

Survey responses of stroke rehabilitation clinicians in Kansas and Missouri $(n=107)$ to specific questions about motor rehabilitation.

\begin{tabular}{|c|c|c|c|c|}
\hline Question & Increase (\%) & $\begin{array}{c}\text { Remain } \\
\text { Constant (\%) }\end{array}$ & Decrease (\%) & Unsure (\%) \\
\hline $\begin{array}{l}\text { 1. In your opinion, what should be done to speed of move- } \\
\text { ment for individuals with high tone? } \\
\text { Velocity should }\end{array}$ & 3 & 21 & 74 & 2 \\
\hline $\begin{array}{l}\text { 2. In your opinion, what should be done to speed of move- } \\
\text { ment for individuals with low tone? } \\
\text { Velocity should }\end{array}$ & 51 & 42 & 4 & 3 \\
\hline
\end{tabular}

other). A majority of the therapists ranked accuracy as the most important aspect followed by strength, number of repetitions, speed, and other.

\section{DISCUSSION}

The stroke rehabilitation methods adopted by therapists vary widely depending on several factors. The availability of a plethora of treatment methods shows that stroke rehabilitation practices are continually evolving. Educators and researchers must obtain data on which stroke rehabilitation methods are actually being used by clinicians. In order to understand the current clinical practices used for rehabilitating patients with stroke, we conducted a survey among the physical and occupational therapists in Kansas and Missouri.

The respondents to our survey averaged more than 12 years of experience treating people with stroke. Nearly all respondents received both Brunnstrom/PNF and Bobath/NDT training in school, and an equal number reported practicing these techniques clinically, despite the lack of evidence to support these approaches [18]. Therapists seem to adopt an eclectic approach and combine principles from different approaches in their current practice, which may indicate the need for an optimal approach to be developed through more research. We find it interesting that even though reeducating normal movement and facilitating adaptation to function represent different treatment approaches, 92 percent of the clinicians agreed 
to both aims. The therapists may be applying both forms of treatment to patients but with different emphases depending on individual conditions.

The clinicians reported that they were inconsistent in reading current literature. In a continuously evolving field like stroke rehabilitation, reading current literature should be an integral part of the clinicians' profession. Reading current literature will enable the clinicians to keep abreast with the latest and most effective rehabilitation practices.

Clinicians suggest that tone should be normalized when facilitating movement. This response is closely tied to the Bobath/NDT approach, which encourages facilitating normal movement patterns while inhibiting tone. Current literature does not favor either Bobath/NDT or Brunnstrom/PNF methods over other treatment options [19-23]. Despite the evidence supporting constraint induced movement therapy (CIMT or CI therapy) [21], only 12 clinicians (11\% of respondents) reported being trained in CIMT and 25 clinicians (23\% of respondents) reported using this efficacious method for treatment. The low percentage of clinicians using CIMT can be attributed to the fact that it is a relatively new technique compared with others such as Bobath/NDT and Brunnstrom/ PNF. This is evident from the fact that only 11 percent learned CIMT in college.

A majority of the therapists (63\%) believed that activities should be delayed if they are reinforcing abnormal movement patterns. However, currently little to no evidence is available that suggests preventing or delaying a patient from moving will worsen abnormal tone and movement $[10,22]$. Therapists responded with uncertainty on whether single-plane movement patterns would ultimately improve function. The reason for this high uncertainty became evident upon examination of the comments of some of the respondents. The wording of the statement does not clearly explain the context and meaning of "single plane."

The survey responses were separated into two groups, physical therapists and occupational therapists, to analyze any differences in their opinions. Upon examination, no significant differences were found between the opinions of physical and occupational therapists. The statement that produced the largest difference of opinion between the physical and occupational therapists is statement 4 in Table 5, where all of the 7 percent of disagreement comes from the physical therapists and no disagreement from the occupational therapists.

\section{LIMITATIONS}

This survey has some limitations, and hence, the results should be subjected to future verification by other methods. We must carefully note that this is a pilot survey that was conducted among therapists $(n=107)$ within the states of Kansas and Missouri. The results from such a narrow sample may not be a true indicator of practices across the nation. However, the results from many sections of the survey showed similarities to the surveys conducted in Sweden, the United Kingdom, and Australia.

The wording of the statements and the corresponding closed responses might have limited the therapists' responses. Some of the respondents in fact added some comments explaining why they were (or were not) choosing a particular answer. Even though the survey was anonymous, we should acknowledge that the respondents' verbal reports about their clinical practice may be different from their actual practice or could have changed after the survey was conducted. Moreover, other studies have shown that clinicians' perception of their practice might be different from their actual practice [23].

Future questionnaires should try to delineate which specific techniques from each of the predominant approaches (Bobath/NDT and Brunnstrom/PNF) are used clinically. Questions directed primarily at upper-limb rehabilitation of stroke might provide clinical context for answering explicit questions. For the statements given in Table 1, the responses show that the comprehensive treatment goal is to improve movement and function. Additional investigation of clinical practices should focus on prioritizing the statements regarding the aim of treatment in stroke rehabilitation.

Regarding statement 3 in Table 4, future queries should aim to determine whether functional practice is performed in a single plane clinically. Additional clarification in relation to "plane" is necessary when discussing movement patterns as well. To resolve any confusion with interpretation, we should define the movement plane with respect to the plane of movement through space, which is not to be confused with the multiplanar perspective of arthrokinematics of joint movement.

\section{CONCLUSIONS}

Our survey on clinical practices in stroke rehabilitation provided data from more than 100 clinicians (physical and occupational therapists combined) in the Midwest. 
The self-reported background information of the clinicians correlates with the dated treatment choices reported in sections of the questionnaire. These data emphasize the need for continuing education of clinicians in efficacious treatments and implementation. Therapists must also continuously scrutinize their beliefs and update their practices as new evidence becomes available. In order to make use of the updated evidence base in their practice, clinicians should be encouraged to actively read professional literature. The uncertainty among clinicians revealed in some sections of the survey shows that more evidence of clinical approaches is needed to ensure efficacious treatments. Development of a comprehensive treatment protocol based on basic and clinical scientific evidence using current therapeutic practices that are supported by the literature should be investigated. Further inquiry into prioritizing treatment approaches and specific components of treatment methods should be instigated. Because of some of the limitations mentioned in the previous section, further investigation should be carried out among a broader group of clinicians spread out across the entire nation in order to substantiate the results of this study.

\section{ACKNOWLEDGMENTS}

We would like to thank the Department of Physical Therapy and Rehabilitation Science and the Department of Occupational Therapy Education at KUMC for assisting in this research by providing databases containing the contact information of physical therapy and occupational therapy clinicians and clinical sites in the states of Kansas and Missouri.

This material was based on work supported by resources of the Information and Telecommunication Technology Center, Lawrence, Kansas.

The authors have declared that no competing interests exist.

\section{REFERENCES}

1. American Stroke Association [home page on the Internet]. Dallas (TX): American Stroke Association; c2008 [updated 2008 Jul 23]. Available from: http://www.strokeassociation.org.

2. Dombovy ML. Rehabilitation and the course of recovery after stroke. In: Whisnant JP, editor. Stroke: Populations, cohorts and clinical trials. Oxford (England): ButterworthHeinemann; 1993. p. 218-37.
3. Broderick JP, Phillips SJ, Whisnant JP, O’Fallon WM, Bergstralh EJ. Incidence rates of stroke in the eighties: The end of the decline in stroke? Stroke. 1989;20(5):577-82.

[PMID: 2718196]

4. Jorgensen HS, Nakayama H, Raaschou HO, Vive-Larsen J, Støier M, Olsen TS. Outcome and time course of recovery in stroke. Part II: Time course of recovery. The Copenhagen stroke study. Arch Phys Med Rehabil. 1995;76(5): 406-12. [PMID: 7741609]

5. Wade DT, Hewer RL. Functional abilities after stroke: Measurement, natural history and prognosis. J Neurol Neurosurg Psychiatry. 1987;50(2):177-82. [PMID: 3572432]

6. Nilsson LM, Nordholm LA. Physical therapy in stroke rehabilitation: Bases for Swedish physiotherapists' choice of treatment. Physiother Theory Pract. 1992;8(1):49-55.

7. Carr JH, Mungovan SF, Shepherd RB, Dean CM, Nordholm LA. Physiotherapy in stroke rehabilitation: Bases for Australian physiotherapists' choice of treatment. Physiother Theory Pract. 1994;10(4):201-9.

8. Sackley CM, Lincoln NB. Physiotherapy treatment for stroke patients: A survey of current practice. Physiother Theory Pract. 1996;12(2):87-96.

9. DeGangi GA, Royeen CB. Current practice among Neuro Developmental Treatment Association members. Am J Occup Ther. 1994;48(9):803-9. [PMID: 7526690]

10. Lennon S. Physiotherapy practice in stroke rehabilitation: A survey. Disabil Rehabil. 2003;25(9):455-61. [PMID: 12745940]

11. Lennon S, Baxter D, Ashburn A. Physiotherapy based on the Bobath concept in stroke rehabilitation: A survey within the UK. Disabil Rehabil. 2001;23(6):254-62. [PMID: 11336098]

12. Latham NK, Jette DU, Coster W, Richards L, Smout RJ, James RA, Gassaway J, Horn SD. Occupational therapy activities and intervention techniques for clients with stroke in six rehabilitation hospitals. Am J Occup Ther. 2006; 60(4):369-78. [PMID: 16915866]

13. Richards LG, Latham NK, Jette DU, Rosenberg L, Smout RJ, DeJong G. Characterizing occupational therapy practice in stroke rehabilitation. Arch Phys Med Rehabil. 2005; 86(12 Suppl 2):S51-S60. [PMID: 16373140]

14. Latham NK, Jette DU, Slavin M, Richards LG, Procino A, Smout RJ, Horn SD. Physical therapy during stroke rehabilitation for people with different walking abilities. Arch Phys Med Rehabil. 2005;86(12 Suppl 2):S41-S50. [PMID: 16373139]

15. Jette DU, Latham NK, Smout RJ, Gassaway J, Slavin MD, Horn SD. Physical therapy interventions for patients with stroke in inpatient rehabilitation facilities. Phys Ther. 2005; 85(3):238-48. [PMID: 15733048$]$

16. Bode RK, Heinemann AW, Semik P, Mallinson T. Patterns of therapy activities across length of stay and impairment levels: Peering inside the "black box" of inpatient stroke 
rehabilitation. Arch Phys Med Rehabil. 2004;85(12):1901-8. [PMID: 15605324]

17. Wang RY, Chen HI, Chen CY, Yang YR. Efficacy of Bobath versus orthopaedic approach on impairment and function at different motor recovery stages after stroke: A randomized controlled study. Clin Rehabil. 2005;19(2): 155-64. [PMID: 15759530]

18. Hafsteinsdóttir TB, Algra A, Kappelle LJ, Grypdonck MH; Dutch NDT Study Group. Neurodevelopmental treatment after stroke: A comparative study. J Neurol Neurosurg Psychiatry. 2005;76(6):788-92. [PMID: 15897499]

19. Luke C, Dodd KJ, Brock K. Outcomes of the Bobath concept on upper limb recovery following stroke. Clin Rehabil. 2004;18(8):888-98. [PMID: 15609844]

20. Lennon S, Ashburn A, Baxter D. Gait outcome following outpatient physiotherapy based on the Bobath concept in people post stroke. Disabil Rehabil. 2006;28(13-14): 873-81. [PMID: 16777775$]$
21. Wolf SL, Winstein CJ, Miller JP, Taub E, Uswatte G, Morris D, Giuliani C, Light KE, Nichols-Larsen D; EXCITE Investigators. Effect of constraint-induced movement therapy on upper extremity function 3 to 9 months after stroke: The EXCITE randomized clinical trial. JAMA. 2006; 296(17):2095-2104. [PMID: 17077374]

22. Pomeroy VM, Tallis RC. Physical therapy to improve movement performance and functional ability post stroke. Part 1: Existing evidence. Rev Clin Gerontol. 2000;10: 261-90.

23. Tyson SF, Selley AB. The effect of perceived adherence to the Bobath concept on physiotherapists' choice of intervention used to treat postural control after stroke. Disabil Rehabil. 2007;29(5):395-401. [PMID: 17364792]

Submitted for publication April 6, 2007. Accepted in revised form March 25, 2008. 